\title{
Comparison of Microneedles and Adhesive-Tape Stripping in Skin Preparation for Epicutaneous Allergen Delivery
}

\author{
Lara Spina $^{a}$ Michael Weisskopfe ${ }^{\mathrm{S}}$ Seraina von Moos ${ }^{c}$ Nicole Graf ${ }^{d}$ \\ Thomas M. Kündig ${ }^{b}$ Gabriela Senti $^{\mathrm{a}}$ \\ ${ }^{a}$ Clinical Trials Center, and Departments of ${ }^{b}$ Dermatology and ${ }^{c}$ Internal Medicine, University Hospital Zurich, \\ Zurich, and d Graf Biostatistics, Winterthur, Switzerland; ${ }^{\mathrm{e}} \mathrm{CRS}$ Clinical Research Services Andernach GmbH, \\ Andernach, Germany
}

\section{Key Words}

Microneedles - Epicutaneous allergen-specific

immunotherapy · Transcutaneous immunotherapy

\begin{abstract}
Background: Epicutaneous immunotherapy targets the network of dendritic cells in the epidermis. Allergen exposure of the dermal layers should be limited as these contain mast cells and blood vessels, which increases the risk for local and systemic allergic reactions. Methods: This intraindividually controlled trial included 20 subjects with birch pollen allergy. Three areas of the volar forearms were treated by repeated adhesive-tape stripping, single-prick lancet piercing and microneedle array application. Four 10-fold dilutions of allergen extract were applied to each area and the IgE-mediated immediate-phase reactions and cell-mediated eczema were assessed. Results: Allergen application after tape stripping led to an immediate-phase reaction in 2 subjects (10\%) at the highest allergen concentration of $10 \mathrm{HEP} / \mathrm{ml}$. Both prick needle and microneedle pretreatment resulted in immediate-phase reactions in all subjects (100\%). The reactivity pattern, however, differed significantly: $95 \%$ of the reactions after pricking occurred at concentrations of $\leq 0.1 \mathrm{HEP} /$ $\mathrm{ml}$, whereas $50 \%$ of the reactions after microneedle prepara-
\end{abstract}

tion were noted at $\geq 1 \mathrm{HEP} / \mathrm{ml}$. In 3 subjects (15\%), eczema was observed on the microneedle-treated skin area. No serious adverse events occurred. Conclusions: Microneedles enhance stratum corneum penetration when compared to tape stripping. However, they do not resolve the problem of mast cell-mediated local reactions, possibly due to diffusion into the dermis. The occurrence of eczema after the microneedle treatment suggests induction of dendritic cellmediated T cell responses. Therefore, skin preparation with microneedles may be a promising method for epicutaneous allergen immunotherapy.

(c) 2015 S. Karger AG, Basel

\section{Introduction}

The prevalence of allergic diseases has been continuously increasing, reaching up to $30 \%$ in industrialized countries [1]. While pharmacotherapy with corticosteroids and antihistamines can efficiently ameliorate IgEmediated symptoms, allergen-specific immunotherapy is still the only disease-modifying treatment available to

\section{L.S. and M.W. share first authorship.}

\section{KARGER 125}

(c) 2015 S. Karger AG, Basel

$1018-2438 / 15 / 1672-0103 \$ 39.50 / 0$

E-Mail karger@karger.com

www.karger.com/iaa
Correspondence to: Dr. Gabriela Senti

Center for Clinical Research, University Hospital Zurich

Rämistrasse 100/MOU2

CH-8091 Zurich (Switzerland)

E-Mail gabriela.senti@usz.ch 
date $[2,3]$. Conventional subcutaneous immunotherapy, however, bears the risk of systemic allergic adverse effects, and has the shortcoming of a low patient acceptance, which is mainly due to the burdensome treatment that requires $50-80$ injections over $3-5$ years [4]. The risk of systemic allergic adverse effects occurs in $3.7 \%$ of individuals or with $1 / 333$ injections $(0.3 \%)$ [5]. Sublingual allergen-specific immunotherapy has been introduced as a safe, noninvasive, alternative route of allergen administration. However, treatment with sublingual application is not of shorter duration, and local (i.e. oral) allergic side effects are frequent, leading to poor treatment adherence $[6,7]$. Epicutaneous immunotherapy is a recently rediscovered route of allergen administration via the epidermis, and results are promising [8-12].

The skin is an attractive administration route for immunotherapy as it is easily accessible and plays an important immunological role [13].

Overcoming the physiological barrier function of the skin is a major challenge for epicutaneous immunotherapy. The 10 - to $20-\mu \mathrm{m}$-thick stratum corneum is impermeable for molecules $>500 \mathrm{Da}$ such as allergens [14]. In recent years, a variety of chemical (azones, alcohols, terpenes and surfactants) [15-18] and physical (electroporation, electrophoresis, phonoresis, tape stripping and mechanical abrasion) [19-22] penetration enhancers have been proposed.

Advances in microtechnology might contribute to improving the situation by allowing for the miniaturization of mechanics and structures. It has been proposed by Henry et al. [23] that microneedles as small as a few 10 s to a few 100s of microns could be used to perforate the stratum corneum. Moreover, it has been shown that microneedles deliver drugs, peptides, antigens and DNA efficiently through the skin [24], and cause significantly less pain than conventional needles [25].

In this study, we assessed the ability of microneedles to overcome the skin barrier, with respect to its potential for use in epicutaneous immunotherapy, by evaluating the allergic skin reactivity to epicutaneous allergen exposure. The conventional skin-prick lancet technique used in allergy testing and tape stripping served as reference methods with respect to skin barrier disruption and safety issues.

\section{Materials and Methods}

\section{Clinical Trial Design}

This study was a monocenter, open-label, intraindividually controlled trial, performed from July to September 2012 at the
Table 1. Study outline

Procedure

Screening/ Follow-up intervention visit

(day 1$)$ (day 4)

Subject information and informed consent $\mathrm{X}$ Pregnancy test

Demographics

Medical history

Concomitant therapy

Inclusion/exclusion criteria

Vital signs

Physical examination

Skin examination

Photography of investigated skin area

Screening prick test

Skin preparation test

Determination of wheal size area

Adverse events

$\mathrm{X}$

$\mathrm{X}$

$\mathrm{X}$

$\mathrm{X}$

$\mathrm{X}$

$\mathrm{X}$

$\mathrm{X}$

$\mathrm{X}$

$\mathrm{X}$

$\mathrm{X}$

$\mathrm{X}$

$\mathrm{X}$

$\mathrm{X}$

$\mathrm{X}$

$\mathrm{X}$

$\mathrm{X}$

University Hospital of Zurich. It was reviewed and approved by the local ethics committee. Written informed consent was obtained from all subjects before enrolment. The study was conducted according to the guidelines of the International Conference on Harmonization of Good Clinical Practice (ICH-GCP) and the Declaration of Helsinki. It was registered at ClinicalTrials.gov before enrolment of the first subject: NCT 01628484.

\section{Study Population}

Twenty subjects were enrolled who fulfilled the following inclusion criteria: birch pollen allergy confirmed by a positive skinprick test, written informed consent, an age of between 18 and 65 years and a positive clinical history for inhalant allergens. Exclusion criteria were: a positive skin reaction in the screening prick test to saline, current allergic symptoms, a history of systemic reactions to allergens, immunotherapy with birch pollen extracts in the past 2 years, skin lesions and excessive hair growth in the skin test areas, treatment with concomitant medications (beta-blockers, ACE inhibitors, tricyclic antidepressants, systemically acting antihistamines or corticosteroids), alcohol or drug abuse, participation in another clinical trial, pregnancy or breastfeeding.

\section{Procedures}

The study comprised 2 visits as outlined in table 1 . After confirmation of reactivity to the birch pollen extract by means of a conventional prick test, 3 skin preparation tests were performed in parallel at predefined areas on the volar forearms (fig. 1). These skin areas were first prepared either by tape stripping, pricking or the application of a microneedle array, and were then exposed to birch pollen allergen extract in 4 ten-fold dilutions, together with a positive and a negative control. After $15 \mathrm{~min}$, the wheal sizes of the skin reactions were measured. The subjects were clinically supervised for $30 \mathrm{~min}$ after the testing procedure. A follow-up visit was performed 3 days later to check for the development of eczematous skin reactions. 
Fig. 1. Testing scheme (from proximal to distal): preparation of the skin of both volar forearms and test solution exposure.

\begin{tabular}{|c|c|c|}
\hline \multirow{2}{*}{$\begin{array}{l}\text { Right volar forearm } \\
\text { Pricking (medial side) }\end{array}$} & \multicolumn{2}{|c|}{ Left volar forearm } \\
\hline & Tape stripping (medial si & Microneedle (lateral \\
\hline Negative Control & Negative Control & Negative Control \\
\hline Size in $\mathrm{mm}^{2} \square \square$ & Size in $\mathrm{mm}^{2} \square \square$ & Size in $\mathrm{mm}^{2} \square \square$ \\
\hline Positive Control & Positive Control & Positive Control \\
\hline Size in $\mathrm{mm}^{2} \square \square$ & Size in $\mathrm{mm}^{2} \square \square$ & Size in $\mathrm{mm}^{2} \square \square$ \\
\hline $0.01 \mathrm{HEP} / \mathrm{ml}$ & $0.01 \mathrm{HEP} / \mathrm{ml}$ & $0.01 \mathrm{HEP} / \mathrm{ml}$ \\
\hline Size in $\mathrm{mm}^{2} \square \square$ & Size in $\mathrm{mm}^{2} \square \square$ & Size in $\mathrm{mm}^{2} \square \square$ \\
\hline $0.1 \mathrm{HEP} / \mathrm{ml}$ & $0.1 \mathrm{HEP} / \mathrm{ml}$ & $0.1 \mathrm{HEP} / \mathrm{ml}$ \\
\hline Size in $\mathrm{mm}^{2} \square \square$ & Size in $\mathrm{mm}^{2} \square \square$ & Size in $\mathrm{mm}^{2} \square \square$ \\
\hline $1 \mathrm{HEP} / \mathrm{ml}$ & $1 \mathrm{HEP} / \mathrm{ml}$ & $1 \mathrm{HEP} / \mathrm{ml}$ \\
\hline Size in $\mathrm{mm}^{2} \square \square$ & Size in $\mathrm{mm}^{2} \square \square$ & Size in $\mathrm{mm}^{2} \square \square$ \\
\hline $10 \mathrm{HEP} / \mathrm{ml}$ & $10 \mathrm{HEP} / \mathrm{ml}$ & $10 \mathrm{HEP} / \mathrm{ml}$ \\
\hline Size in $\mathrm{mm}^{2} \square \square$ & Size in $\mathrm{mm}^{2} \square \square$ & Size in $\mathrm{mm}^{2} \square \square$ \\
\hline
\end{tabular}

\section{Testing Products and Skin Preparation Techniques}

Microneedle Array. The solid Microstructured Transdermal System by $3 \mathrm{M}^{\circledR}$ (St. Paul, Minn., USA) was used to induce a large number of microchannels with an expected depth of $<100 \mu \mathrm{m}$ into the epidermis (fig. 2). This system is a small patch of 351 microneedles, marketed in the USA as a skin preparation device for the transdermal application of topical products. The arrays show excellent durability to repeated in vivo application with $<5 \%$ of the structures showing even minimal tip bending after 16 applications [26]. The microneedle array was applied according to the instructions of the supplier. A weight of $1 \mathrm{~kg}$ was put onto the microneedle patch in order to generate the recommended force of $10 \mathrm{~N}$.

Tape. A conventional self-adhesive tape was used (Tesafilm ${ }^{\circledR}$ ) for the tape stripping skin preparation. The tape was gently pressed onto the skin, followed by fast removal. The procedure was repeated 6 times, each time with a new piece of tape.

Prick Lancet. Conventional sterile prick lancets (length $1 \mathrm{~mm}$ ) by Entaco Ltd. (Redditch, Worcestershire, UK, distributed by Stallergenes ${ }^{\circledR}$ ) were used for the skin-prick preparation. The pricking was performed similar to conventional prick testing, but before applying the allergen extract.

Test Solutions. Registered birch pollen allergen extract (Betula verrucosa; Soluprick ${ }^{\circledR}$, ALK-Abelló A/S, Hørsholm, Denmark) was used in 4 ten-fold dilutions, i.e. $10,1,0.1$ and $0.01 \mathrm{HEP} / \mathrm{ml}$. The 10-HEP concentration corresponds to the standard prick test concentration. Histamine $(10 \mathrm{mg} / \mathrm{ml})$ served as a positive control and excipient solution served as a negative control

\section{Assessment of Skin Reactivity}

Skin reactivity was the primary end point of the study and was evaluated by measuring the wheal size of the IgE-mediated imme-

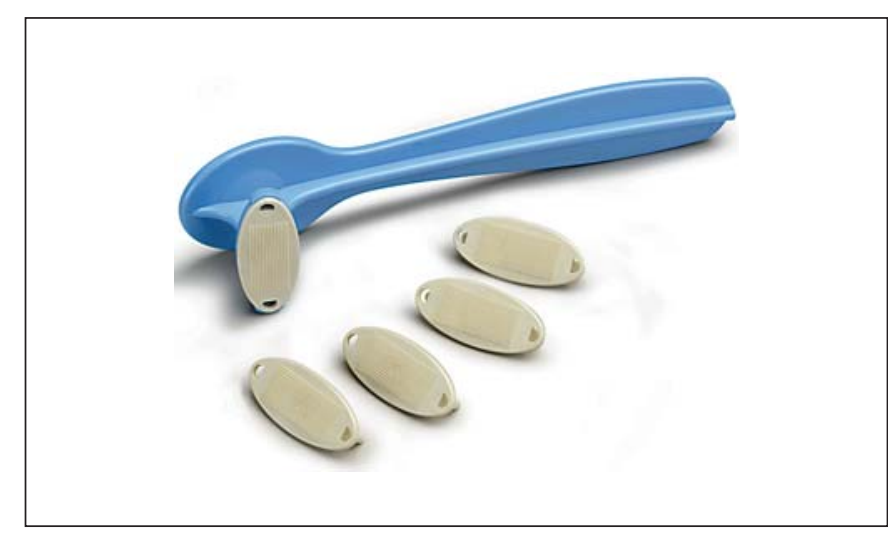

Fig. 2. Microneedle array with applicator (Solid Microstructured Transdermal System, 3M).

diate-phase reaction. For this purpose, the wheals were encircled with a pen and the markings transferred with a scotch tape onto paper. The circular marks were scanned together with a reference area of $1 \mathrm{~cm}^{2}$. The wheal size could be calculated in $\mathrm{mm}^{2}$ by comparing the pixel number of the reference area with that of the wheal. The presence of an immediate-phase reaction was defined as a wheal size $>0 \mathrm{~mm}^{2}$ or greater than the reaction in the negative control, respectively.

Cell-mediated eczematous reactions, i.e. the appearance of erythema, vesicules or papules were assessed at the follow-up visit after 3 days. 


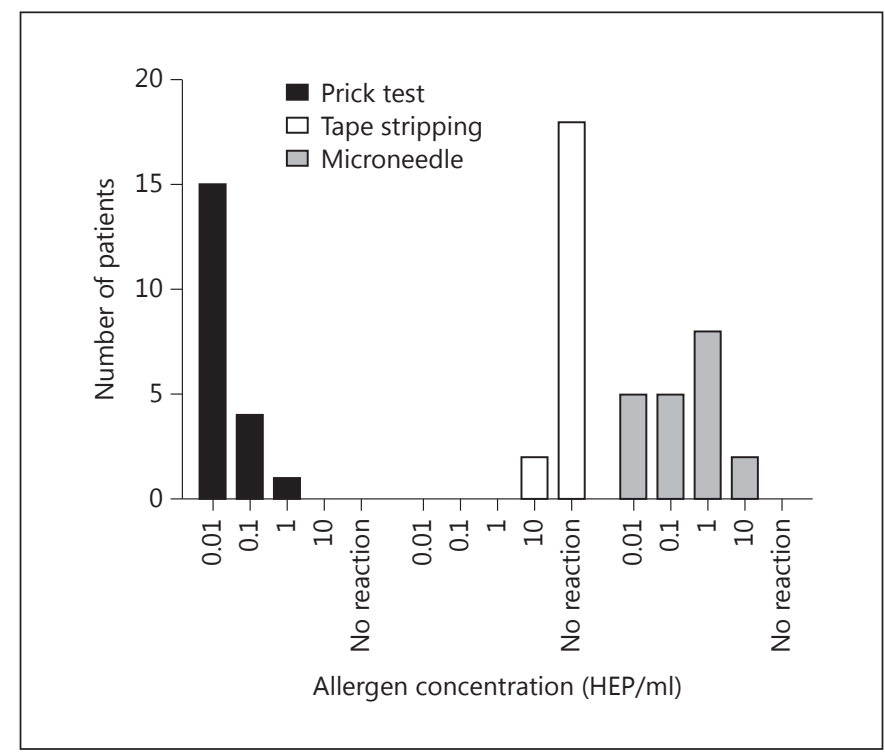

Fig. 3. Number of patients reacting with a wheal at allergen concentrations of $0.01,0.1,1$ and $10 \mathrm{HEP} / \mathrm{ml}$ and those not reacting at all.

Safety Assessment

All adverse events during the study were recorded.

\section{Statistical Analysis}

In view of the explorative nature of this study, no sample size calculation was performed. According to the Nordic Council on Medicine, allergen standardization requires 20 evaluable subjects; thus, it was assumed that a sample size of 20 would be sufficient to compare the different skin preparation techniques [27].

We investigated at which minimal allergen concentration a reaction occurred at all. If no reaction was seen at the highest concentration, the next higher ten-fold dilution $(=100 \mathrm{HEP} / \mathrm{ml})$ was assumed to be provoking a reaction. The Friedman test and the exact Wilcoxon signed-ranks test tested for differences in skin reactivity between the skin preparation methods.

Cellular responses were described with the absolute and relative frequency and were compared in a paired design with the Cochran Q test.

\section{Results}

\section{Subject Characteristics}

In total, 31 subjects were screened, 11 of whom were screening failures and thus considered not suitable for enrolment into the study. Twenty subjects (64\%) were enrolled and completed the study without protocol deviations. Twelve study participants were female $(60 \%)$ and 8 were male (40\%). The age of the subjects ranged from 18 to 54 years, on average $29.4 \pm 8.91$ years.

\section{Skin Reactivity}

Preparation by tape stripping yielded an immediatephase reaction in 2 cases $(10 \%)$ and only at the highest concentration $(10 \mathrm{HEP} / \mathrm{ml})$. In contrast, all subjects (100\%) reacted after both the skin-prick and microneedle preparations (fig. 3). The reactivity pattern differed between these 2 techniques: $95 \%$ of the reactions after pricking occurred at concentrations of $\leq 0.1 \mathrm{HEP} / \mathrm{ml}$, whereas $50 \%$ of the reactions after the microneedle preparation were noted as $\geq 1 \mathrm{HEP} / \mathrm{ml}$. The reaction pattern was thus significantly different between the 3 skin preparation techniques $(\mathrm{p}<0.001)$. Moreover, all pairwise comparisons were also highly significant (prick test-tape stripping: $p<0.001$, prick test-microneedle: $p=0.001$ and tape stripping-microneedle: $\mathrm{p}<0.001)$.

Only $3 / 20$ subjects (15\%) had abnormal findings on their volar forearms that could be attributed to eczema. One subject developed reactions on all allergen-exposed test areas of the skin-prick and microneedle testing (fig. 4). Two subjects showed a reaction only at the highest concentration after the microneedle test. However, the Cochran Q test did not indicate a significant difference between the 3 skin preparation techniques with respect to the frequency distribution of eczema $(\mathrm{p}=0.222)$.

\section{Safety}

Apart from the intended skin reactions at the allergen application site, i.e. wheals (fig. 3), and eczema in 3/20 patients, only 1 adverse event (headache) was reported which was classified as mild and unrelated. No serious adverse events occurred during the study.

\section{Discussion}

The study objective was to assess the usefulness of microneedles as a skin preparation technique for epicutaneous immunotherapy. Microneedle preparation was compared to conventional skin pricking for allergen testing and the tape stripping used in our first clinical trials with epicutaneous immunotherapy (table 2).

Skin-prick needles, with a length of $1 \mathrm{~mm}$ designed to deliver the allergen to the upper dermal layers [28], induced an immediate skin reaction via mast cell activation in all subjects, with minimal allergen concentration of $0.01 \mathrm{HEP} / \mathrm{ml}$, indicating highly efficient penetration of the stratum corneum. Skin pricking is considered to be extremely safe with systemic allergic reactions observed in $<0.02 \%$ of subjects $[28,29]$, indicating that the access to the systemic vasculature is very small. 
Fig. 4. Allergic skin reactivity of the microneedle-prepared skin. Visit 1: immediate-phase reactions (scan) 15 min after application of test solutions. Visit 2: cellular reaction (eczema) at the corresponding sites (photo) $72 \mathrm{~h}$ after application. No reaction at negative control (not shown).

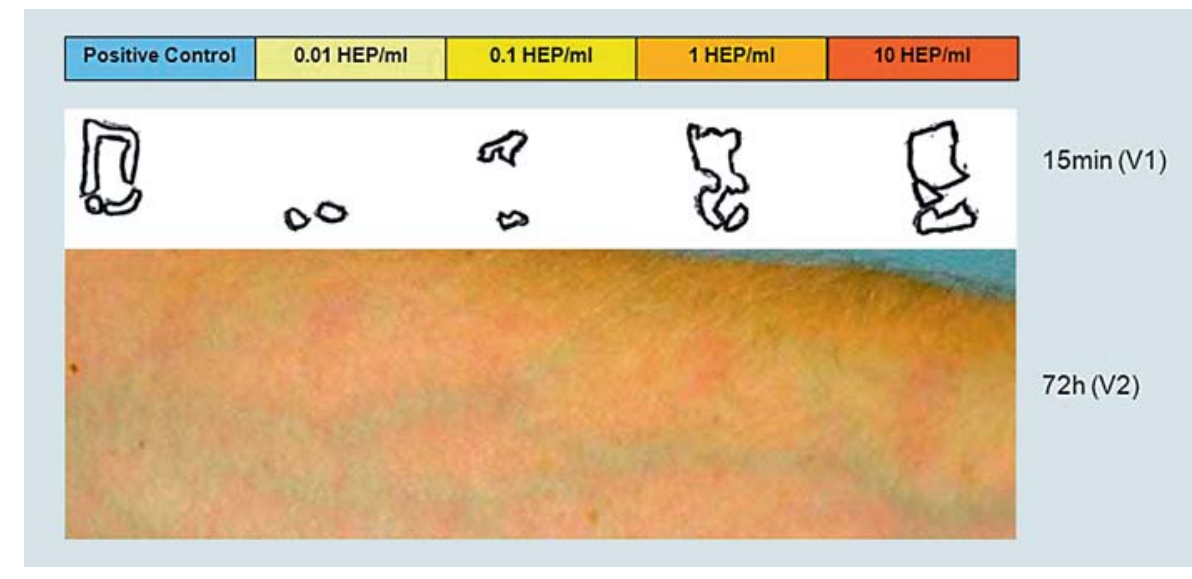

Table 2. Overview of skin preparation techniques

\begin{tabular}{|c|c|c|c|}
\hline & \multicolumn{3}{|l|}{ Device } \\
\hline & tesa scotch tape & microneedles & prick lancet \\
\hline Penetration depth & upper epidermal layers & $100 \mu \mathrm{m}$ & $1 \mathrm{~mm}$ \\
\hline Skin layer & $\begin{array}{l}\text { deeper skin layers via } \\
\text { concentration gradient } \\
\text { diffusion }\end{array}$ & $\begin{array}{l}\text { deep epidermal layers (dense } \\
\text { network of Langerhans cells), deeper } \\
\text { skin layers via concentration gradient } \\
\text { diffusion }\end{array}$ & $\begin{array}{l}\text { dermis (mast cells, blood } \\
\text { vessels, dermal dendritic cells) }\end{array}$ \\
\hline Preferential reaction & & $\begin{array}{l}\text { activation of humoral and cellular } \\
\text { immune response via antigen } \\
\text { presentation, initiated by Langerhans } \\
\text { cells }\end{array}$ & $\begin{array}{l}\text { histamine-related immediate- } \\
\text { phase reaction, mediated by } \\
\text { the cross-linking of mast cell- } \\
\text { attached IgE }\end{array}$ \\
\hline Activation of immune response & + & +++ & + \\
\hline Local side effects & + & ++ & +++ \\
\hline Systemic side effects & - & - & - \\
\hline
\end{tabular}

Skin pretreatment with microneedles of $<100 \mu \mathrm{m}$ in length, designed to deliver antigen in the epidermal layers, also induced immediate reactions in all of the tested subjects. However, the majority of patients only reacted with higher allergen concentrations $(\mathrm{p}<0.001)$, indicating that less allergens reached the dermal, mast cell-rich layers. Moreover, the observation of eczematous reactions in 3 individuals might indicate that the allergen was preferentially deposited in the epidermal skin layer with its high density of antigen-presenting Langerhans cells. These findings are well-explained by the structural properties of the microneedle patch and of the skin. The typical thickness of the stratum corneum is $15-20 \mu \mathrm{m}$ and the total thickness of the epidermis is $50-150 \mu \mathrm{m}$. The fact that the penetration depth of the microneedles is $<100 \mu \mathrm{m}$ implies that they reliably disrupt the stratum corneum, but may just reach down to the dermoepidermal junction, so that most of the allergen is primarily deposited into the epidermis $[26,30]$. However, the flare and wheal formation caused by mast cells in the dermis clearly demonstrates that the allergen rapidly diffuses into the dermis.

Adhesive-tape stripping, in contrast, has been shown to reduce the stratum corneum and to enhance the penetration of topically applied substances into deeper layers of the epidermis [31]. However, the relatively low reactivity pattern in this study suggests that allergen deposition rates are significantly lower than with the microneedle preparation $(\mathrm{p}<0.001)$. This is in line with the results of another tape stripping epicutaneous immunotherapy study, where a statistically significant amelioration of hay 
fever symptoms was only achieved with high allergen concentrations (100 HEP/ml) [32].

Although promising, further enhancement of efficacy may therefore be desirable, either by using chemical adjuvants or physical penetration-enhancing techniques that precisely target epidermal antigen-presenting cells while minimizing penetration to the dermal layers.

As demonstrated by this study, the use of microneedles shows promise. In addition to preferential deposition of allergen in epidermal layers, the mechanical stress to keratinocytes enhances the activation of keratinocytes with consecutive secretion of cytokines (IL-1, IL-6, IL-8, TNF- $\alpha$ and IFN- $\gamma$ ). This promotes efficient pulsing, maturation and emigration of the epidermal and/or dermal dendritic cells to the draining lymph, as assumed from observation of cellular reactions at the microneedle sites in 3 cases. Allergen exposure to the dermal layers that contain nerve endings, mast cells and blood vessels could not be prevented by using microneedles with a penetration depth of $<100 \mu \mathrm{m}$. Nevertheless, as these micronee- dles do not reach down and cut into the vascular plexus of the dermis, allergen diffusion is the driving force, with the expected local allergic reactions (erythema and wheal formation), whereas systemic allergic reactions due to the direct access of the allergen into the vascular plexus is extremely rare. Therefore, it is to be expected that the risk for inadvertent intravascular allergen administration and consequent systemic allergic reactions should be reduced when compared to allergen administration using a conventional needle and syringe, such as in subcutaneous immunotherapy. With epicutaneous immunotherapy with a microneedle, which is able to overcome the stratum corneum efficiently, we created a situation comparable to sublingual allergen-specific immunotherapy, where the allergen is directly administered to the mucosal cells, missing the stratum corneum; this is a method with frequently reported local side effects but very rare systemic allergic reactions that allows for safe self-administration by patients [33]. Larger studies are needed to prove this assumption.

\section{References}

>1 Asher MI, Montefort S, Bjorksten B, Lai CK, Strachan DP, Weiland SK, Williams H: Worldwide time trends in the prevalence of symptoms of asthma, allergic rhinoconjunctivitis, and eczema in childhood: ISAAC phases one and three repeat multicountry cross-sectional surveys. Lancet 2006;368:733-743.

-2 Akdis M, Akdis CA: Therapeutic manipulation of immune tolerance in allergic disease. Nat Rev Drug Discov 2009;8:645-660.

$\checkmark 3$ Holgate ST, Polosa R: Treatment strategies for allergy and asthma. Nat Rev Immunol 2008;8: 218-230.

$>4$ Frew AJ: Allergen immunotherapy. J Allergy Clin Immunol 2010;125:S306-S313.

5 Moreno C, Cuesta-Herranz J, FernandezTavora L, Alvarez-Cuesta E: Immunotherapy safety: a prospective multi-centric monitoring study of biologically standardized therapeutic vaccines for allergic diseases. Clin Exp Allergy 2004;34:527-531.

-6 Cox LS, Larenas Linnemann D, Nolte H, Weldon D, Finegold I, Nelson HS: Sublingual immunotherapy: a comprehensive review. J Allergy Clin Immunol 2006;117:1021-1035.

-7 Senna G, Lombardi C, Canonica GW, Passalacqua G: How adherent to sublingual immunotherapy prescriptions are patients? The manufacturers' viewpoint. J Allergy Clin Immunol 2010;126:668-669.

-8 Senti G, Graf N, Haug S, Ruedi N, von Moos S, Sonderegger T, Johansen P, Kündig TM: Epicutaneous allergen administration as a novel method of allergen-specific immuno- therapy. J Allergy Clin Immunol 2009;124: 997-1002.

$\checkmark 9$ Senti G, Freiburghaus AU, Kundig TM: Epicutaneous/transcutaneous allergen-specific immunotherapy: rationale and clinical trials. Curr Opin Allergy Clin Immunol 2010;10: 582-586.

10 Senti G, von Moos S, Kundig TM: Epicutaneous allergen administration: is this the future of allergen-specific immunotherapy? Allergy 2011;66:798-809.

11 Agostinis F, Forti S, Di Berardino F: Grass transcutaneous immunotherapy in children with seasonal rhinoconjunctivitis. Allergy 2010;65:410-411.

-12 Dupont C, Kalach N, Soulaines P, LegoueMorillon S, Piloquet H, Benhamou PH: Cow's milk epicutaneous immunotherapy in children: a pilot trial of safety, acceptability, and impact on allergic reactivity. J Allergy Clin Immunol 2010;125:1165-1167.

13 Streilein JW: Skin-associated lymphoid tissues (SALT): origins and functions. J Invest Dermatol 1983;80(suppl):12s-16s.

14 Bos JD, Meinardi MM: The 500 Dalton rule for the skin penetration of chemical compounds and drugs. Exp Dermatol 2000;9:165169.

15 Pilgram GS, van der Meulen J, Gooris GS, Koerten HK, Bouwstra JA: The influence of two azones and sebaceous lipids on the lateral organization of lipids isolated from human stratum corneum. Biochim Biophys Acta 2001;1511:244-254.
16 Pershing LK, Lambert LD, Knutson K: Mechanism of ethanol-enhanced estradiol permeation across human skin in vivo. Pharm Res 1990;7:170-175.

17 Tupker RA, Pinnagoda J, Nater JP: The transient and cumulative effect of sodium lauryl sulphate on the epidermal barrier assessed by transepidermal water loss: inter-individual variation. Acta Derm Venereol 1990;70:1-5.

18 Fang JY, Hung CF, Chiu HC, Wang JJ, Chan TF: Efficacy and irritancy of enhancers on the in-vitro and in-vivo percutaneous absorption of curcumin. J Pharm Pharmacol 2003;55: 1175.

19 Denet AR, Vanbever R, Preat V: Skin electroporation for transdermal and topical delivery. Adv Drug Deliv Rev 2004;56:659-674.

20 Mitragotri S, Kost J: Low-frequency sonophoresis: a review. Adv Drug Deliv Rev 2004;56: 589-601.

21 Loffler H, Dreher F, Maibach HI: Stratum corneum adhesive tape stripping: influence of anatomical site, application pressure, duration and removal. Br J Dermatol 2004;151: 746-752.

22 Frerichs DM, Ellingsworth LR, Frech SA, Flyer DC, Villar CP, Yu J, Glenn GM: Controlled, single-step, stratum corneum disruption as a pretreatment for immunization via a patch. Vaccine 2008;26:2782-2787.

23 Henry S, McAllister DV, Allen MG, Prausnitz MR: Microfabricated microneedles: a novel approach to transdermal drug delivery. J Pharm Sci 1998;87:922-925. 
24 Coulman S, Allender C, Birchall J: Microneedles and other physical methods for overcoming the stratum corneum barrier for cutaneous gene therapy. Crit Rev Ther Drug Carrier Syst 2006;23:205-258.

25 Gill HS, Denson DD, Burris BA, Prausnitz MR: Effect of microneedle design on pain in human volunteers. Clin J Pain 2008;24:585594.

26 Duan D, Moeckly C, Gysbers J, Novak C, Prochnow G, Siebenaler K, Albers L, Hansen $\mathrm{K}$ : Enhanced delivery of topically-applied formulations following skin pre-treatment with a hand-applied, plastic microneedle array. Curr Drug Deliv 2011;8:557-565.

27 Nordic Council on Medicines: Registration of Allergenic Preparations. Nordic guidelines, ed 2. Uppsala, NLN Publications, 1989, vol 23, pp 1-34.
28 Heinzerling L, Mari A, Bergmann KC, Bresciani M, Burbach G, Darsow U, et al: The skin prick test - European standards. Clin Transl Allergy 2013;3:3.

29 Liccardi G, D’Amato G, Canonica GW, Salzillo A, Piccolo A, Passalacqua G: Systemic reactions from skin testing: literature review. J Investig Allergol Clin Immunol 2006;16:7578.

30 Bal SM, Ding Z, van Riet E, Jiskoot W, Bouwstra JA: Advances in transcutaneous vaccine delivery: do all ways lead to Rome? J Control Release 2010;148:266-282.
31 Dickel H, Goulioumis A, Gambichler T, Fluhr JW, Kamphowe J, Altmeyer P, Kuss O: Standardized tape stripping: a practical and reproducible protocol to uniformly reduce the stratum corneum. Skin Pharmacol Physiol 2010; 23:259-265.

32 Senti G, von Moos S, Tay F, Graf N, Sonderegger T, Johansen P, Kündig TM: Epicutaneous allergen-specific immunotherapy ameliorates grass pollen-induced rhinoconjunctivitis: a double-blind, placebo-controlled dose escalation study. J Allergy Clin Immunol 2012;129: 128-135.

-33 Canonica GW, Bousquet J, Casale T, Lockey RF, Baena-Cagnani CE, Pawankar R, et al: Sub-lingual immunotherapy: World Allergy Organization Position Paper 2009. Allergy 2009;64(suppl 91):1-59. 